\title{
Molecular and Computational Studies of Trichoderma Isolates
}

\author{
Ved Ratan ${ }^{1}$, Mukesh Srivastava ${ }^{2}$, Supriya Dixit ${ }^{3} *$ D.K. Srivastava ${ }^{4}$, \\ Shubha Trivedi ${ }^{3}$ and Yatindra Kumar Srivastava ${ }^{1}$
}
${ }^{I}$ Department of Plant Pathology, Chandra Shekhar Azad University of Agriculture and Technology, Kanpur (208002), India
${ }^{2}$ Rani Laxmi Bai Central Agricultural University, Jhansi (U.P.) 284003, India
${ }^{3}$ Biocontrol Lab, Department of Plant Pathology, Chandra Shekhar Azad University of Agriculture \& Technology, Kanpur 208002, India
${ }^{4}$ Council of Science and Technology, Lucknow, India

*Corresponding author

\begin{tabular}{|c|c|}
\hline & A B S T R A C T \\
\hline $\begin{array}{l}\text { 5.8S ribosomal } \\
\text { RNA gene, } \\
\text { Trichoderma, ITS, } \\
\text { TrichoKey, } \\
\text { TrichoBLAST }\end{array}$ & \multirow{3}{*}{$\begin{array}{l}\text { Most isolates of the genus Trichoderma were found to act as mycoparasites of many } \\
\text { economically important aerial and soil-borne plant pathogens. Trichoderma has gained } \\
\text { importance as a substitute for chemical pesticides and hence an attempt was intended to } \\
\text { corroborate the positive relatedness of molecular and morphological characters. Fungal } \\
\text { strains of Trichoderma BSAs were isolated collected from four different districts of Uttar } \\
\text { Pradesh, India. The universal primers were used for amplification of 5.8SrRNA gene } \\
\text { fragment and the strain was characterized by using 5.8SrRNA gene sequence with the help } \\
\text { of ITS marker. It is proposed that the identified isolates assigned as the species of the } \\
\text { genus Trichoderma based on TrichoKey analysis together with the 5.8SrRNA gene } \\
\text { sequence search in Ribosomal Database Project, small subunit rRNA and large subunit } \\
\text { rRNA databases. Thus the molecular markers can be employed to identify a superior strain } \\
\text { of Trichoderma for its commercial exploitation. }\end{array}$} \\
\hline Article Info & \\
\hline $\begin{array}{l}\text { Accepted: } \\
\text { 22 January } 2019 \\
\text { Available Online: } \\
\text { 10 February } 2019\end{array}$ & \\
\hline
\end{tabular}

\section{Introduction}

Trichoderma species have been investigated as biological control agents (BCAs) for over 70 years (Hjeljord and Tronsmo, 1998) but it is only recently that strains have become commercially available. This is largely a result of the change in public attitude toward the use of chemical pesticides and fumigants (Anonymous, 1995). Knowledge concerning the behavior of these fungi as antagonists is essential for their effective use since they can act against target organisms in several ways (Jeffries and Young, 1994). Strains of Trichoderma can produce extracellular enzymes (Haran et al., 1996) and antifungal antibiotics (Ghisalberti and Rowland, 1993), but they may also be competitors to fungal pathogens (Simon and Sivasithamparan, 1989), promote plant growth (Inbar et al., 1994), and induce resistance in plants (De Meyer et al., 1998). 
Morphological characterization of fungi is not as specific as the genotyping methods as this enables to determine species of fungus. Genotypic techniques involve the amplification of a phylogenetically informative target, such as the small-subunit (5.8S) rRNA gene reported by Woese et al., (1977). Genes codes for rRNA are conserved in all fungal genome and other kingdoms which is essential for the survival of cells. The sequences of the rRNA and proteins comprising the ribosome are highly conserved throughout evolution, because they require complex inter- and intra molecular interactions to maintain the proteinsynthesizing machinery reported by Sacchi et al., (2002), Hillis et al., (1991) and Woese et al., (1987).

Trichoderma sp. is among the most frequently isolates soil fungi and present in plant root ecosystem and they adversely affect the population of pathogenic microorganism. They can also compete with other soil microorganisms for nutrients and space. Furthermore, they inhibit or degrade pectinase and other enzymes that are essential for plantpathogenic fungi (cook and baker, 1983). They are cosmopolitan and versatile in nature. They have high bio-diversities and have been extensively studied as a model microorganism to analyze and explored its antagonistic action against the phytopathogens.

A great number of fascinating characters of Trichoderma are responsible for its biocontrol potential. To know the potential characters of Trichoderma species, the internal transcribed spacer (ITS) region of the rDNA sequencing is done. It has typically been most useful for molecular systematic study at species level, and even within species found by OspinaGiraldo et al., (1998), Kubicek et al., (2000), Kulling-Gradinger et al., (2002) and Lee et al., (2002) attempted a first phylogenetic analysis of the whole genus of Trichoderma using sequence analysis of the ITS region of rDNA.

The present study was carried out to distinguish strains of Trichoderma by using 5.8S rRNA gene sequence as reported in bacterial rRNA gene found by Srivastava $e t$ al., (2008) to characterize collected isolates.

\section{Materials and Methods}

\section{Molecular characterization of Trichoderma isolates}

\section{DNA extraction}

Five Trichoderma isolates (CST-02, CST-05, CST-09, CST-21 and CST-22) were subjected for molecular identification and for their DNA isolation, 15-20 days old mycelial mat was harvested by filtering through Whatman filter paper no. 42, air dried to remove excess of moisture and lyophilized. A genomic DNA was extracted by using Cetrimide Tetradecyl Trimethyl Ammonium Bromide (CTAB) mini extraction method with minor modification. Agarose gel electrophoresis technique was used to check whether the DNA was present in sample or not. The quality of DNA was confirmed by using $0.8 \%$ agarose gel with ethidium bromide. $10 \mu$ l of DNA was loaded in electrophoresis unit and run at $60 \mathrm{~V}$. Then gel was visualized in trans-illuminator over ultra violet light.

\section{PCR amplification}

PCR-amplification reactions were performed in a $50 \mathrm{ml}$ mixture containing $50 \mathrm{mM} \mathrm{KCl}, 20$ $\mathrm{mM}$ Tris $\mathrm{HCl}$ (pH 8.4), $2.0 \mathrm{mM} \mathrm{MgCl} 2,200$ $\mathrm{mM}$ of each of the four deoxinucleotide triphosphates (dNTPs), $0.2 \mu \mathrm{mM}$ of each primer, $40 \mathrm{mg} / \mathrm{ml}$ of template and $2.5 \mathrm{U}$ of Taq polymerase. The cycle parameters included an initial denaturation at $94^{\circ} \mathrm{C}$ for 5 
min, followed by 40 cycles of denaturation at $94^{\circ} \mathrm{C}$ for $1 \mathrm{~min}$, primer annealing at $55^{\circ} \mathrm{C}$ for $2 \mathrm{~min}$ and primer extension at $72^{\circ} \mathrm{C}$ for $3 \mathrm{~min}$ and a final extension for $10 \mathrm{~min}$ at $72^{\circ} \mathrm{C}$. Amplified products were separated on $1.2 \%$ agarose gel in TAE buffer, pre-stained with ethidium bromide $(1 \mathrm{mg} / \mathrm{ml})$ and electrophoresis was carried out at 60 volts for 3 hours in TAE buffer.

One kb ladder (MBI, Fermentas) was used as a marker. The gel was observed in a transilluminator over ultra violet light. The desired bands were cut from the gel with minimum quantity of gel portion using QIAGEN gel extraction kit. The quality of samples was verified on agarose gel electrophoresis and will be sent for sequencing to MTTC, Chandigarh.

Once the strains are isolated in wet lab and their morphology is studied based on which the strain identification is done, the identification of isolated strains is done and validated at the ISTH website. As ISTH is solely dedicated for the identification of different strains of Trichoderma and Hypocrea species based on ITS sequences and other taxonomical data, the strains under study in this project are also validated through ISTH database.

ISTH (International Sub-commission on Trichoderma and Hypocrea Taxonomy), a Sub-commission of ICTF (International Commission on the Taxonomy of Fungi), hosts an online method for the quick molecular identification of Hypocrea/Trichoderma species based on an oligonucleotide barcode: a diagnostic combination of several oligonucleotides (hallmarks) specifically allocated within the internal transcribed spacer 1 and 2 (ITS1 and 2) sequences of rDNA repeat. It helps in identifying specific strains of Trichoderma by comparing the sequence with the database by locating genus specific hallmarks (GSH).
The nucleotide sequences (submitted and retrieved from NCBI) of all six Trichoderma species are analyzed through TrichOKEY 2 program for their validation post molecular identification. This has confirmed the selected sequences as specific strains of Trichoderma species. A set of 5 oligonucleotide sequences which are present in all known Hypocreal Trichoderma ITS1 - 5.8S RNA - ITS2 sequences, is used in combinations to identify the species at generic level.

A comparison of the 5.8SrRNA gene sequence of the test strain was done using BLAST against non-redundant nucleotide (nr/nt) database observed by Thompson et al., (1994). A number of Trichoderma sequences were selected on the basis of a similarity score of equal or above from $90 \%$ with database sequences.

Multiple sequence alignment of these selected homologous sequences and 5.8SrRNA gene sequence of test strain was performed using Clustal W reported by Saitou et al., (1987). Subsequently, an evolutionary distance matrix was then generated from these nucleotide sequences in the dataset. A phylogenetic tree was then drawn using the Neighbour Joining method reported by Tamura et al., (2007).

\section{Results and Discussion}

\section{Molecular analysis using Internal Transcribed Spacer region (ITS) and Sequence Analysis}

At species level microorganisms are difficult to distinguish morphologically, so molecular methods including DNA sequencing and phylogenetic species recognition using several unlinked genes are needed to give accurate identification of microorganism. Molecular identification has important advantages over conventional techniques of microscopic examination. 
Ribosomal RNA (rRNA) sequence analysis has been well-documented as a means of determining phylogenetic relationships in the entire major organism. Variable sequences within the mature small subunit (SSU) and large subunit (LSU) rRNA genes have been found to be appropriate for assessing subgeneric relationships in many eukaryotes. One of these variable regions, the $\mathrm{D}_{2}$ region of the LSU, has been used to determine phylogenetic relationships in a number of pathogenic fungal genera. The ITS region of the rDNA operon, which is more variable than the $D_{2}$ region, has proven useful in distinguishing relationships at the species level.

The genetic variability within 05 Trichoderma isolates of collected from four different geographic location of Uttar Pradesh. A total of five isolates were sequenced which contains $400-500 \mathrm{bp}$ of the 5.8SrRNA gene and used for the identification of isolated fungal strain.

The phylogenetic relationship was established among all five Trichoderma species with the help of the sequence data obtained from the Internal Transcribed spacer 1 (ITS1) region. Further the TrichOKEY and TrichoBLAST analysis is done and it was seen that all five sequences regions are similar to Genus Trichoderma (Table 1 and 2).

Phylogenetic relationship among Trichoderma isolates based on sequence analysis of the internal transcribed spacer region

Molecular phylogenetics is the branch of phylogeny that analyses hereditary molecular differences, mainly in DNA sequences, to gain information on an organism's evolutionary relationships. The result of a molecular phylogenetic analysis is expressed in a phylogenetic tree.
The primary objective of molecular phylogenetic studies is to recover the order of evolutionary events and represent them in evolutionary trees that graphically depict relationships among species or genes over time. Kindermann et al., (1998) attempted a first phylogenetic analysis of the whole genus of Trichoderma using sequence analysis of the ITS1 region of rDNA.

Bio-control agent Trichoderma has attained importance for substitute of chemical pesticides and hence an attempt was intended to corroborate the positive relatedness of molecular and morphological characters. The fungal strains of Trichoderma spp. was isolated from the different location and collected from rhizosphere soil of four different district of Uttar Pradesh, India. The universal ITS primers were used for amplification of the 18S rRNA gene fragment and strain characterized by using $18 \mathrm{~S}$ rRNA gene sequence with the help of ITS marker.

The primers (ITS1 to ITS4) were used for amplifying ITS regions, followed by sequencing, for all the five Trichoderma isolates. The resulting amplicons of approximately ranges from $400 \mathrm{bp}-500 \mathrm{bp}$ were obtained in all the Trichoderma isolates. The sequences of these amplified products showed 90-100\% identity with other documented sequences of Trichoderma strains in the BLASTN search. The ITS nucleotide sequences obtained with ITS primers were used for the construction of phylogenetic trees.

All the ITS sequences of Trichoderma isolates as well as taken for multiple alignment and fall into three clusters in the Neighbor Joining (NJ) tree. Cluster $\mathrm{I}$ is divided into 2 subgroups in first subgroup CST-05 and CST-09 and in second subgroup CST-22 occurred. In cluster II CST-02 and in cluster III CST-21 only occur (Figure 1). 
Table.1 TrichOKEY results (in detail) representing the location of Gene Specific Hallmarks (GSHs)

\section{Analysing sequence: CST-05}

First anchor was not found ....

Second anchor (GSH) was found in position $\mathbf{4 1 7} \ldots$

Third anchor was not found ....

Fourth anchor was not found ....

Fifth anchor was not found ....

Found $\mathbf{1}$ genus-specific hallmarks (Anchors):

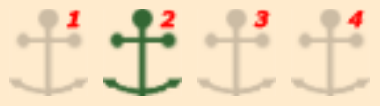

Barcode identification of the query sequence is not possible because only one genus specific hallmark (Anchor 2) is found. It may mean that either you have submitted an incomplete ITS1 fragment or the query sequence does not belong to Hypocrea/Trichoderma.

\section{Analysing sequence: CST-09}

First anchor was not found ....

Second anchor (GSH) was found in position $\mathbf{4 1 6} \ldots$.

Third anchor was not found ....

Fourth anchor was not found ....

Fifth anchor was not found ....

Found $\mathbf{1}$ genus-specific hallmarks (Anchors):

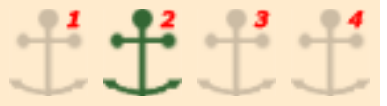

Barcode identification of the query sequence is not possible because only one genus specific hallmark (Anchor 2) is found. It may mean that either you have submitted an incomplete ITS1 fragment or the query sequence does not belong to Hypocrea/Trichoderma.

\section{Analysing sequence: CST-21}

First anchor was not found ....

Second anchor (GSH) was found in position $414 \ldots$.

Third anchor was not found ....

Fourth anchor was not found ....

Fifth anchor was not found ....

Found $\mathbf{1}$ genus-specific hallmarks (Anchors):

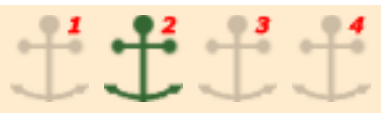

Barcode identification of the query sequence is not possible because only one genus specific hallmark (Anchor 2) is found. It may mean that either you have submitted an incomplete ITS1 fragment or the query sequence does not belong to Hypocrea/Trichoderma. 


\section{Analysing sequence: CST-22}

First anchor was not found ....

Second anchor (GSH) was found in position $414 \ldots$.

Third anchor was not found ....

Fourth anchor was not found ....

Fifth anchor was not found ....

Found 1 genus-specific hallmarks (Anchors):

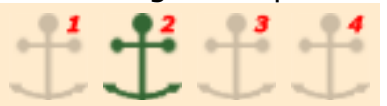

Barcode identification of the query sequence is not possible because only one genus specific hallmark (Anchor 2) is found. It may mean that either you have submitted an incomplete ITS1 fragment or the query sequence does not belong to Hypocrea/Trichoderma.

Table.2 TrichoBLAST results (in detail)

Query: Isolate CST-02 Shows \% closest similarity with Trichoderma asperellum (99.5\%) ITS/5.8s rRNA gene sequence data

Database: isthdb 674 sequences; 315,818 total letters

\section{Sequence producing significant alignment:}

>isth|116|T.asperellum|ITS1 and 2|CBS433.97 Length $=446$

Score $=779$ bits (393), Expect $=0.0$

Identities $=413 / 417(99 \%)$, Gaps $=2 / 417(0 \%)$

Query: Isolate CST-05 Shows \% closest similarity with Trichoderma koningiopsis (99.7\%) ITS/5.8s rRNA gene sequence data

Database: isthdb 674 sequences; 315,818 total letters

\section{Sequence producing significant alignment:}

>isth|911|T.koningiopsis|ITS1 and 2|GJS93-20

$$
\text { Length }=515
$$

Score $=898$ bits (453), Expect $=0.0$

Identities $=460 / 461(99 \%)$, Gaps $=1 / 461(0 \%)$

Query: Isolate CST-09 Shows \% closest similarity with Trichoderma asperellum (100\%) ITS/5.8s rRNA gene sequence data

Database: isthdb 674 sequences; 315,818 total letters 
Sequence producing significant alignment:

>isth|116|T.asperellum|ITS1 and 2|CBS433.97

Length $=446$

Score $=882$ bits (445), Expect $=0.0$

Identities $=445 / 445(100 \%)$

Query: Isolate CST-21 Shows \% closest similarity with Trichoderma asperellum (99.5\%)

ITS/5.8s rRNA gene sequence data

Database: isthdb

674 sequences; 315,818 total letters

Sequence producing significant alignment:

>isth|936|T.theobromicola|ITS1 and 2|DIS85f

Length $=533$

Score $=864$ bits (436), Expect $=0.0$

Identities $=468 / 475(98 \%)$

Query: Isolate CST-22 Shows \% closest similarity with Trichoderma asperellum (99.5\%)

ITS/5.8s rRNA gene sequence data

Database: isthdb

674 sequences; 315,818 total letters

Sequence producing significant alignment:

$>$ isth|116|T.asperellum|ITS1 and 2|CBS433.97

Length $=446$

Score $=839$ bits (423), Expect $=0.0$

Identities $=443 / 447(99 \%)$

Figure.1 The evolutionary history (Phylogram) was inferred using nearly complete ITS sequences ( $500 \mathrm{bp})$ using ITS 1 and 4 primers constructed by Neighbour-Joining method

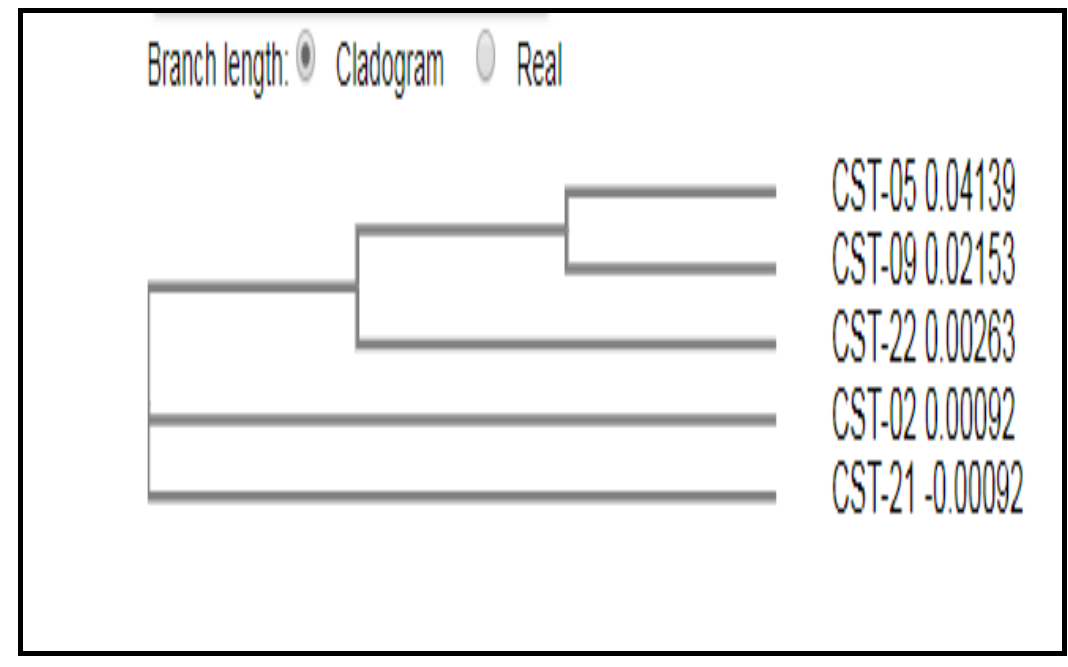


In conclusion the Trichoderma isolates were collected from four different districts of Uttar Pradesh and were further subjected to molecular characterization followed by TrichOKEY and TrichoBLAST analysis which strongly suggests that the isolates belongs to Trichoderma genus and phylogenetic analysis had been done in order to analyse evolutionary relationship among Trichoderma strains. Thus it is concluded that by using biotechnological and bioinformatics integrated approaches helpful to identify a superior strain of Trichoderma for developing a new bioformulation for the management of different soil and seed borne diseases.

\section{Acknowledgement}

The authors are grateful to the financial support granted by the Council of Science \& Technology, Lucknow.

\section{Conflict of interest}

Authors declare that they have no conflict of interest.

\section{References}

Abd-El-Khair, H. R., Khalifa, K. M., Karima, H. E., Haggag., 2010. Effect of Trichoderma spp. on damping off diseases incidence, some plant enzymes activity and nutritional status of bean plants. J. American Sci. 6 (9):486-497.

Agrios, G. N., 2005. Plant Pathology. (5th Edition). Elsevier Academic Publishers, Boston. 922pp.

Anonymous, 1995. United Nations Environment Programme. 1994 Report of Methyl Bromide Technical Options Committee. Montreal protocol on substances that deplete ozone layer. Nairobi, Kenya: United Nations Ozone Secretariat.
De Meyer, G., Bigirimana, J., Elad, Y., Hofte, M., 1998. Induced systemic resistance in Trichoderma harzianum T39 biocontrol of Botrytis cinerea. Eur J Plant Pathol. 104:279-286.

Haran, S., Schickler, H., Chet, I., 996. Molecular mechanisms of lytic enzymes involved in the biocontrol activity of Trichoderma harzianum. Microbiology. 142:2321-2331.

Hillis, D. M., Moritz, C., Porter, C. A., Baker, R. J., 1991. Evidence for biased gene conversion in concerted evolution of ribosomal DNA. Science. 251: 308310.

Hjeljord, L., Tronsmo, A., 1998. Trichoderma and Gliocladium in biocontrol: an overview. In: Kubicek C P, Harman G E, editors. Trichoderma and Gliocladium. London, United Kingdom: Taylor \& Francis, Ltd., pp. 135- 151 .

Inbar, J., Abramshy, D., Cohen, D., Chet, I., 1994. Plant growth enhancement and disease control by Trichoderma harzianum in vegetable seedlings grown under commercial conditions. Eur J Plant Pathol. 100:337-346.

Kindermann, J., Ayouti, Y. E., Samuels, G. J., Kubicek, C. P., 1998. Phylogeny of the genus Trichoderma based on sequence analysis of the internal transcribed spacer region 1 of the rDNA cluster. Fungal GenBiol. 24: 298-309.

Kubicek, C. P., Mach, R. L., Peterbauer, C. K., Lorito, M., 2000. Trichoderma From genes to biocontrol. J Plant Pathol. 83: 11-23.

Ospina-Giraldo, M. D., Royse, D. J., Thon, M. R., Chen, X., Romaine, C.P., 1998. Phylogenetic relationships of Trichoderma harzianum causing mushroom green mold in Europe and North America to other species of Trichoderma from world-wide 
sources. Mycologia. 90: 76-81.

Padmadaya, B., and Reddy, H. R., 1996. Screening of Trichoderma spp. against Fusarium oxysporum f.sp. lycopersici causing wilt on tomato. Indian Journal of Mycology and Plant Pathology. 26: 288-290.

Sacchi, C. T., Whitney, A. M., Reeves, M. W., Mayer, L. W., Popovic, T., 2002. Sequence Diversity of Neisseria meningdidis 16S rRNA Genes and Use of $16 \mathrm{~S}$ rRNA Gene Sequencing as a Molecular Subtyping Tool. J Clin Microbiol. 40(12): 4520-4527.

Saitou, N., Nei, M., 1987. The neighborjoining method: a new method for reconstructing phylogenetic trees. MolBiolEvol. 4(4): 406-25.

Simon, A., Sivasithamparan, K., 1989. Pathogen suppression: a case study of Gaeumannomyces graminis var. tritici in soil. Soil Biol Biochem. 21:331337.

Srivastava, S., Singh, V., Kumar, V., Verma, P. C., Srivastava, R., Basu, V., Gupta,
V., Rawat, A. K., 2008. Identification of regulatory elements in 16S rRNA gene of Acinetobacter species isolated from water sample. Bioinformation. 3(4):173-176.

Tamura, K., Dudley, J., Nei, M., Kumar, S., 2007. MEGA4: Molecular Evolutionary Genetics Analysis (MEGA) software version 4.0. Mol. BiolEvol. 24(8):1596-99.

Thompson, J. D., Higgins, D. G., Gibson, T. J., 1994. CLUSTAL W: improving the sensitivity of progressive multiple sequence alignment through sequence weighting, position-specific gap penalties and weight matrix choice. Nucleic Acids Res. 22(22):4673-80.

Woese, C. R., Fox, G.E., 1997. Phylogenetic structure of the prokaryotic domain: the primary kingdoms. Proc Natl Acad Sci USA. 74: 5088-5090.

Woese, C.R., 1987. Bacterial evolution. Microbiol Rev. 51:221-271.

\section{How to cite this article:}

Ved Ratan, Mukesh Srivastava, Supriya Dixit, D.K. Srivastava, Shubha Trivedi and Yatindra Kumar Srivastava. 2019. Molecular and Computational Studies of Trichoderma Isolates. Int.J.Curr.Microbiol.App.Sci. 8(02): 3282-3290. doi: https://doi.org/10.20546/ijcmas.2019.802.383 